\section{(A) Check for updates}

Cite this: Dalton Trans., 2017, 46, 16000

Received 15th September 2017, Accepted 26th October 2017

DOI: $10.1039 / c 7 d t 03470 a$

rsc.li/dalton

\section{Construction of molecular rectangles with titanium-oxo clusters and rigid aromatic carboxylate ligands $\uparrow$}

\author{
Qing-Rong Ding, ${ }^{a}$ Jin-Xiu Liu, ${ }^{a}$ Nagaraju Narayanam, ${ }^{\text {a,b }}$ Lei Zhang (D *a and \\ Jian Zhang (iD a
}

\begin{abstract}
Four rectangular molecular architectures have been successfully constructed using $\left\{\mathrm{Ti}_{5} \mathrm{O}_{7}\right\}$ clusters as inorganic vertical edges and bridging aromatic carboxylates as horizontal edges. The introduced organic ligands show a strong influence on the light absorption behaviors of the obtained hybrid complexes.
\end{abstract}

Regular-shape coordination complexes are an important class of advanced molecular materials because of their numerous and diverse applications in probes ${ }^{1}$ host-guest chemistry, ${ }^{2}$ catalysis, ${ }^{3,4}$ molecular devices, ${ }^{5,6}$ and photocatalysis. ${ }^{7}$ The fabrication of various nanoscale molecular architectures such as triangles, squares, pentagons, hexagons, cages, and boxes has been well reported so far. ${ }^{8-11}$ But the structures of molecular rectangles are relatively difficult to assemble and very few reports are known to date. ${ }^{12}$ Stang and co-workers successfully synthesized a nanoscopic molecular rectangle by the selfassembly of a pre-designed Pt-based molecular clip and symmetrical dipyridyl ligands. ${ }^{13}$ Furthermore, it still remains a challenge to prepare polymetallic components containing molecular rectangles.

As an important raw material, titanium dioxide $\left(\mathrm{TiO}_{2}\right)$ has found wide application in pigments, sunscreens and toothpaste $^{14,15}$ and has also shown great potential in the global renewable energy arena with regard to environmental and solar energy applications. ${ }^{16-18}$ Along this line, polyoxo-titanium clusters (PTCs) have been attracting much research attention in recent years, because they possess well-defined structures and can be used as reactivity model compounds of $\mathrm{TiO}_{2}$ nanoparticles. ${ }^{19-25}$

\footnotetext{
${ }^{a}$ State Key Laboratory of Structural Chemistry, Fujian Institute of Research on the Structure of Matter, The Chinese Academy of Sciences, Fuzhou, Fujian 350002, P. R. China.E-mail:LZhang@fjirsm.ac.cn

${ }^{b}$ International College, University of Chinese Academy of Sciences, 100049 Beijing, China

$\dagger$ Electronic supplementary information (ESI) available: Materials, synthesis, physical measurements and Cif files. CCDC 1572540 (PTC-121), 1572541 (PTC-122), 1572542 (PTC-123), and 1572543 (PTC-124). For ESI and crystallographic data in CIF or other electronic format see DOI: 10.1039/c7dt03470a
}

Another major advantage of PTCs is that they can be easily functionalized by organic ligands. ${ }^{26}$ In the course of our research on titanium-oxo clusters, recently, we successfully applied a variety of bridging ligands to organize the $0 \mathrm{D}\left\{\mathrm{Ti}_{6}\right\}$ clusters $^{27,28}$ into 1D, 2D, and 3D materials with polynuclear copper halides. ${ }^{29}$ Furthermore, we also prepared some molecular cluster series with metal-oxo subunits and bridging organic ligands. ${ }^{30}$ But there are not yet any reports on the crystal structures of PTCs with rectangle shaped architectures.

In this work, we report four polyoxo-titanium molecular clusters, namely $\mathrm{Ti}_{10}\left(\mu_{2}-\mathrm{O}\right)_{2}\left(\mu_{3}-\mathrm{O}\right)_{2}\left(\mu_{2}-\mathrm{O}^{\mathrm{i}} \mathrm{Pr}\right)_{6}(\mathrm{sac})_{4}(\mathrm{bdc})_{2}\left(\mathrm{O}^{\mathrm{i}} \mathrm{Pr}\right)_{14}$ (PTC-121; $\mathrm{H}_{2} \mathrm{Sac}=$ salicylic acid; $\mathrm{H}_{2}$ bdc = terephthalic acid; $\mathrm{HO}^{\mathrm{i}} \mathrm{Pr}=$ isopropanol $), \mathrm{Ti}_{10}\left(\mu_{2}-\mathrm{O}\right)_{2}\left(\mu_{3}-\mathrm{O}\right)_{2}\left(\mu_{2}-\mathrm{O} \operatorname{Pr}\right)_{6}(\mathrm{sac})_{4}\left(2-\mathrm{NH}_{2}-\right.$ bdc $)_{2}\left(\mathrm{O}^{\mathrm{i}} \mathrm{Pr}\right)_{14}$ (PTC-122; 2- $\mathrm{NH}_{2}-\mathrm{H}_{2}$ bdc $=$ 2-aminoterephthalic acid), $\mathrm{Ti}_{10}\left(\mu_{2}-\mathrm{O}\right)_{2}\left(\mu_{3}-\mathrm{O}\right)_{2}\left(\mu_{2}-\mathrm{O}^{\mathrm{i}} \mathrm{Pr}\right)_{6}(\mathrm{npc})_{4}(\mathrm{bdc})_{2}\left(\mathrm{O}^{\mathrm{i}} \mathrm{Pr}\right)_{14}$ (PTC-123; $\mathrm{H}_{2} \mathrm{npc}=$ 1-hydroxy-2-naphthoic acid $), \mathrm{Ti}_{10}\left(\mu_{2}-\mathrm{O}\right)_{2}\left(\mu_{3}-\mathrm{O}\right)_{2}\left(\mu_{2}-\right.$ $\left.\mathrm{O}^{\mathrm{i}} \mathrm{Pr}\right)_{6}(\mathrm{npc})_{4}\left(2-\mathrm{NH}_{2}-\mathrm{bdc}\right)_{2}\left(\mathrm{O}^{\mathrm{i}} \mathrm{Pr}\right)_{14}$ (PTC-124) with such kinds of rectangle shaped architectures. Salicylic acid and 1-hydroxy-2naphthoic acid (Scheme 1a and b) were chosen as stabilizing ligands and terephthalic acid and 2-aminoterephthalic acid were employed as bridging ligands (Scheme 1c and d) to form these new molecular clusters. The crystal structure arrange-

\title{
Stabilizing ligands:
}<smiles>O=C(O)c1ccccc1O</smiles>

(a)<smiles>O=C(O)c1ccc2ccccc2c1O</smiles>

(b)

Bridging ligands:

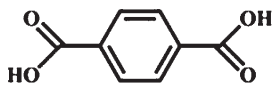

(c)

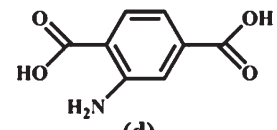

(d)
Scheme 1 Illustration of the applied stabilizing and bridging ligands: (a) salicylic acid $\left(\mathrm{H}_{2} \mathrm{Sac}\right)$; (b) 1-hydroxy-2-naphthoic acid $\left(\mathrm{H}_{2} \mathrm{npc}\right)$; (c) terephthalic acid ( $\mathrm{H}_{2}$ bdc); (d) 2-amino terephthalic acid (2- $\mathrm{NH}_{2}-\mathrm{H}_{2}$ bdc). 
ments of metal-oxo building units and their bonding patterns with different ligands are discussed in brief. To the best of our knowledge, these are the first example of PTCs with crystal structures having rectangle like architectures. Moreover, the light absorption behaviors of these four molecular clusters are well investigated and the influence of organic ligands is explained in detail.

Through the solvothermal reaction of salicylic acid, terephthalic acid and $\mathrm{Ti}\left(\mathrm{O}^{\mathrm{i}} \mathrm{Pr}\right)_{4}$ in isopropanol at $80{ }^{\circ} \mathrm{C}$ for three days, colorless crystals of PTC-121 were obtained with a high yield. PTC-122 to PTC-124 are also synthesized under similar reaction conditions by changing the combinations of bridging and stabilizing ligands (experimental details in the ESI $\dagger$ ). All of these reactions produced four pairwise isomorphic structural analogues that can be categorized into two pairs (PTC-121 \& PTC-122: Pair-I; PTC-123 \& PTC-124: Pair-II) of molecular clusters. X-ray crystallography analysis reveals that PTC-121 and PTC-122 are crystallized in the monoclinic $P 2_{1} / c$ space group, while PTC-123 and PTC-124 are crystallized in trigonal $R \overline{3}$ space group. In all four compounds, a common metal-oxo building unit $\left(\mathrm{Ti}_{3}\right)$ is observed that has been reported earlier in many molecular clusters (Fig. 1a and 2a). ${ }^{26}$ As shown in Fig. 1a, the trinuclear unit is formed by the combination of three titanium atoms and one $\mu_{3}-\mathrm{O}$ atom, one $\mu_{2}-\mathrm{O}$ atom and one $\mu_{2}-\mathrm{O}^{\mathrm{i}} \mathrm{Pr}$ atom. Each of these three titaniums is further terminally bonded with one isopropanol group. These trinuclear units are extended on both sides with additional titaniums to form a pentanuclear moiety. The additional titanium atoms are attached through the stabilizing ligands and $\mu_{2}-\mathrm{O}^{\mathrm{i}} \mathrm{Pr}$ atoms. All the titaniums in this building unit are six coordinated, exhibiting slightly distorted octahedral coordination geometries. The Ti-O distances are in the range from 1.751(3) to 2.208(3) $\AA$ and are all in reasonable ranges (Table S2 $\dagger$ ). The flipping of combinations of stabilizing ligands produced two types of pentanuclear moieties with decorated $\mathrm{H}_{2} \mathrm{Sac}$ and $\mathrm{H}_{2}$ npc ligands at their corners, respectively. Furthermore, the bridging ligands are attached on the upper (a)

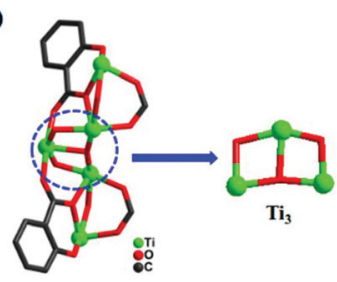

(c)

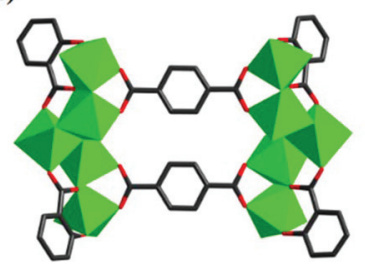

(b)

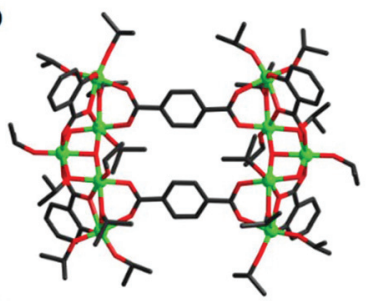

(d)

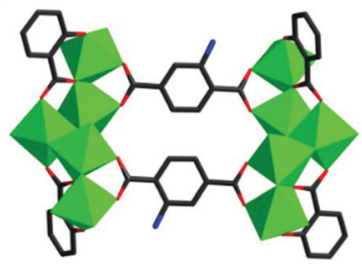

Fig. 1 The sac- $\left\{\mathrm{Ti}_{5}\right\}$ unit in PTC-121 (a) and molecular structures of PTC-121 (b, c) and PTC-122 (d). (a)

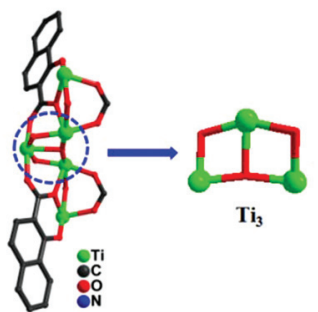

(c)

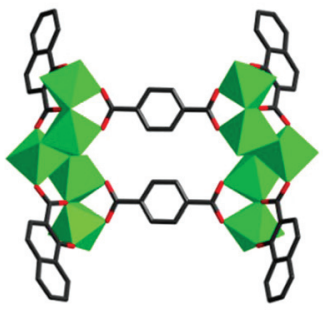

(b)

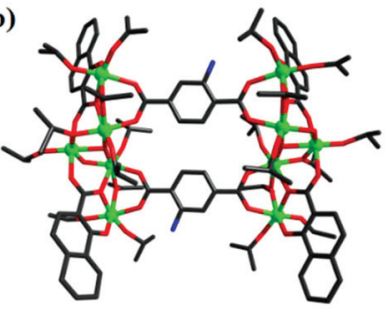

(d)

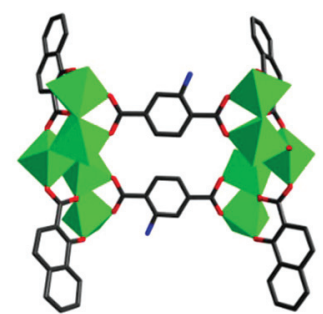

Fig. 2 The npc- $\left\{\mathrm{Ti}_{5}\right\}$ unit in PTC-124 (a) and molecular structures of PTC-124 (b, d) and PTC-123 (c).

and lower parts of these pentanuclear moieties by bonding each carboxylic acid to two titanium atoms. Two such kinds of bridging ligands are involved in bonding to form the decanuclear molecular clusters with four stabilizing ligands in total (Fig. 1b). Similar kinds of structural arrangements are observed in all the four molecular clusters synthesized in this work.

To easily understand the rectangular shapes of these molecular clusters, the pentanuclear building units decorated with stabilizing ligands are regarded as vertical edges and the bridging ligands as horizontal edges (Fig. 1c). When the horizontal bridging bdc ligand was replaced by $2-\mathrm{NH}_{2}$-bdc, PTC-122 was prepared (Fig. 1d), which also has similar bonding and coordination arrangements as PTC-121. Interestingly, through the substitution of the stabilizing sac ligands by npc, the second pair of molecular clusters (PTC-123 and PTC-124) are obtained with bdc and $\mathrm{NH}_{2}$-bdc, respectively (Fig. 2c and d).

According to the above results, a novel and efficient synthetic strategy is employed to assemble the $\left\{\mathrm{Ti}_{5}\right\}$ subunits with a series of different functional ligands to form four related molecular clusters with rectangular shapes. The structural characteristics of the $\left\{\mathrm{Ti}_{5}\right\}$ units might be advantageous for accessing all functional $\mathrm{Ti}^{4+}$ sites for different applications. It is also important to mention that the stabilizing ligands (sac and $\mathrm{npc}$ ) have two functional groups at neighboring positions and will assist the easy formation of pre-nucleation clusters in the reaction solutions. Such an effective cluster formation could enhance the chances of constructing symmetrical structures. Additionally, the bridging ligands (bdc and 2- $\mathrm{NH}_{2}$-bdc) have their coordinating groups at symmetrical positions to assist the bonding of two subunits on both sides of the rectangle. The successful synthesis of these molecular clusters with rectangle like architectures has proved that employing both asymmetrical and symmetrical ligands in a single pot reaction can form highly symmetrical crystal structures.

Diffuse reflectance spectroscopic measurements were carried out on four compounds to understand their optical 


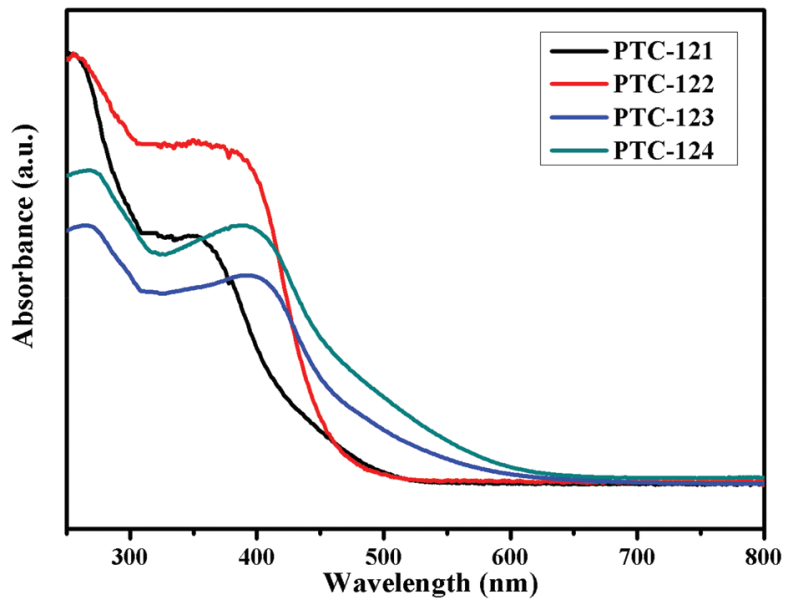

Fig. 3 The solid-state UV-vis absorption spectra of PTC-121 to PTC-124.

absorption properties (Fig. 3). The optical bandgaps calculated for PTC-121 to PTC-124 were $2.84 \mathrm{eV}, 2.71 \mathrm{eV}, 2.55 \mathrm{eV}$, and 2.43 $\mathrm{eV}$, respectively. It is interesting to find that the higher wavelength absorption (300-450 $\mathrm{nm}$ ) by PTC-122 is much stronger than that for PTC-121. The same tendency is also observed between PTC-124 and PTC-123. This is believed to be due to the additional $-\mathrm{NH}_{2}$ group in the bridging $2-\mathrm{NH}_{2}$-bdc ligand for PTC-122 and PTC-124. ${ }^{31}$ It is also interesting to learn that there is a big bandgap reduction of $0.29 \mathrm{eV}$ between PTC-121 and PTC-123 with the same bridging bdc ligands. Similarly, the reduction between PTC-122 and PTC-124 is $0.28 \mathrm{eV}$. Such bandgap reduction might be attributed to the naphthalene group in PTC-123 and PTC-124. Due to the presence of both naphthalene in the stabilizing ligands and $-\mathrm{NH}_{2}$ group in the bridging ligands, the largest bandgap reduction between PTC-121 and PTC-124 is found to be $0.41 \mathrm{eV}$.

In summary, two pairs of molecular rectangles containing similar inorganic Ti-O building units and rigid organic ligands have been successfully synthesized. By the crossed combination of two pairs of stabilizing and bridging ligands, the $\left\{\mathrm{Ti}_{5}\right\}$ subunits can be readily formed and linked into rectangular structures. Moreover, these molecular clusters display diverse ligand dependent light absorption characteristics. Our results provide an intriguing and effective concept of using titanium-oxo clusters as building blocks for the construction of beautiful rectangular architectures.

\section{Conflicts of interest}

There are no conflicts to declare.

\section{Acknowledgements}

This work was supported by the NSFC (21473202 and 21673238), the Strategic Priority Research Program of the
Chinese Academy of Sciences (XDB20000000) and the FJKJT (2017J06009).

\section{References}

1 T. Yoshii, K. Mizusawa, Y. Takaoka and I. Hamachi, J. Am. Chem. Soc., 2014, 136, 16635.

2 R. Yu, X. F. Kuang, X. Y. Wu, C. Z. Lu and J. P. Donahue, Coord. Chem. Rev., 2009, 253, 2872.

3 J. A. Mata, F. E. Hahn and E. Peris, Chem. Sci., 2014, 5, 1723.

4 Y. Xu, Y. Ye, T. Liu, X. Wang, B. Zhang, M. Wang, H. Han and C. Li, J. Am. Chem. Soc., 2016, 138, 10726.

5 P. Zhang, M. Wang, C. Li, X. Li, J. Dong and L. Sun, Chem. Commun., 2010, 46, 8806.

6 Y. Guan, Y. Qin, Y. Sun, J. Chen, W. Xu and D. Zhu, Chem. Commun., 2016, 52, 4846.

7 G. F. Manbeck and K. J. Brewer, Coord. Chem. Rev., 2013, 257,1660 .

8 M. Ruben, J. Rojo, F. J. Romero-Salguero, L. H. Uppadine and J.-M. Lehn, Angew. Chem., Int. Ed., 2004, 43, 3644.

9 T. R. Cook, Y. R. Zheng and P. J. Stang, Chem. Rev., 2013, 113, 734.

10 Y. F. Han, W. G. Jia, W. B. Yu and G. X. Jin, Chem. Soc. Rev., 2009, 38, 3419.

11 A. Schmidt, A. Casini and F. E. Kühn, Coord. Chem. Rev., 2014, 275, 19.

12 P. Thanasekaran, R. T. Liao, Y. H. Liu, T. Rajendran, S. Rajagopal and K. L. Lua, Coord. Chem. Rev., 2005, 249, 1085.

13 C. L. Kuehl, S. D. Huang and P. J. Stang, J. Am. Chem. Soc., 2001, 123, 9634.

14 A. Weir, P. Westerhoff, L. Fabricius and N. von Goetz, Environ. Sci. Technol., 2012, 46, 2242.

15 A. Al-Kattan, A. Wichser, R. Vonbank, S. Brunner, A. Ulrich, S. Zuind and B. Nowack, Environ. Sci.: Processes Impacts, 2013, 15, 2186.

16 X. Chen and A. Selloni, Chem. Rev., 2014, 114, 9281.

17 X. Chen, C. Li, M. Grätzel, R. Kostecki and S. S. Mao, Chem. Soc. Rev., 2012, 41, 7909.

18 X. Chen, L. Liu and F. Huang, Chem. Soc. Rev., 2015, 44, 1861.

19 P. Coppens, Y. Chen and E. Trzop, Chem. Rev., 2014, 114, 9645.

20 P. D. Matthews, T. C. King and D. S. Wright, Chem. Commun., 2014, 50, 12815.

21 Y. Lv, J. Willkomm, A. Steiner, L. Gan, E. Reisner and D. S. Wright, Chem. Sci., 2012, 3, 2470.

22 W. H. Fang, L. Zhang and J. Zhang, J. Am. Chem. Soc., 2016, 138, 7480.

23 M. Y. Gao, F. Wang, Z. G. Gu, D. X. Zhang, L. Zhang and J. Zhang, J. Am. Chem. Soc., 2016, 138, 2556.

24 G. Fornasieri, L. Rozes, S. L. Calvé, B. Alonso, D. Massiot, M. N. Rager, M. Evain, K. Boubekeur and C. Sanchez, J. Am. Chem. Soc., 2005, 127, 4869.

25 J. B. Benedict and P. Coppens, J. Am. Chem. Soc., 2010, 132, 2936. 
26 L. Rozes and C. Sanchez, Chem. Soc. Rev., 2011, 40, 29 W.-H. Fang, J.-F. Wang, L. Zhang and J. Zhang, Chem. 1006. Mater., 2017, 29, 2681.

27 M. Czakler, C. Artner and U. Schubert, Eur. J. Inorg. Chem., 30 M.-Y. Gao, W.-H. Fang, T. Wen, L. Zhang and J. Zhang, 2014, 2014, 2038. Cryst. Growth Des., 2017, 17, 3592.

28 J. X. Liu, M. Y. Gao, W. H. Fang, L. Zhang and J. Zhang, 31 Y. Fu, D. Sun, Y. Chen, R. Huang, Z. Ding, X. Fu and Z. Li, Angew. Chem., Int. Ed., 2016, 55, 1. Angew. Chem., Int. Ed., 2012, 124, 3420. 